\title{
Reliable estimation of antimicrobial use and its evolution between 2010 and 2013 in French swine farms
}

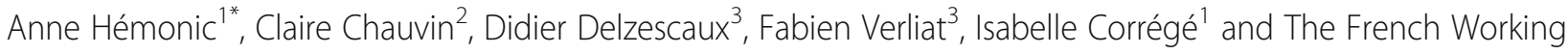
Group 'antimicrobials in the swine industry

\begin{abstract}
Background: There has been a strong implication of both the French swine industry and the national authorities on reducing the use of antimicrobials in swine production since 2010. The annual monitoring of antimicrobial sales by the French Veterinary Medicines Agency (Anses-ANMV) provides estimates but not detailed figures on actual onfarm usage of antimicrobials in swine production.

Results: In order to provide detailed information on the 2010 and 2013 antimicrobial use in the French swine industry, the methodology of cross-sectional retrospective study on a representative sample of at least 150 farms has been elected. The analysis of the collected data shows a strong and significant decrease in antimicrobial exposure of pigs between 2010 and 2013. Over three years, the average number of days of treatment significantly decreased by $29 \%$ in suckling piglets and by $19 \%$ in weaned piglets. In fattening pigs, the drop (-29\%) was not statistically significant. Only usage in sows did increase over that period (+ $17 \%$, non-significant), which might be associated with the transition to group-housing of pregnant sows that took place at the time. Also, over that period, the use of third- and fourth generation cephalosporins in suckling piglets decreased by $89 \%$, and by $82 \%$ in sows, which confirms that the voluntary moratorium on these classes of antimicrobials decided at the end of 2010 has been effectively implemented.

Conclusions: The methodology of random sampling of farms appears as a precise and robust tool to monitor antimicrobial use within a production animal species, able to fulfil industry and national authorities' objectives and requirements to assess the outcome of concerted efforts on antimicrobial use reduction. It demonstrates that the use of antimicrobials decreased in the French swine industry between 2010 and 2013, including the classes considered as critical for human medicine.
\end{abstract}

Keywords: Swine, Antimicrobial consumption, DDD, ALEA, 'One health'

\section{Background}

Antimicrobial resistance is a global concern that ought to be tackled by a 'One Health' approach [1]. In the veterinary domain, this has driven the implementation of monitoring programmes of antimicrobial resistance levels and antimicrobial usage [2], especially in Europe $[3,4]$, where sales data are collected in nearly all Member States [3].

\footnotetext{
* Correspondence: anne.hemonic@ifip.asso.fr

${ }^{1}$ IFIP-Institut du porc, Domaine de la Motte au Vicomte, 35104, 35651 Le

Rheu, BP, France

Full list of author information is available at the end of the article
}

In France, sales data on antimicrobial veterinary medicinal products (VMPs) have been collected yearly since 1999 by the National Veterinary Medicines Agency (Anses-ANMV). Data were first expressed as volumes (tons of active compounds), before being converted in exposure units [4,5]. Since 2009, attribution of VMPs sales to each animal production species is provided by manufacturers [5]. In 2011, the French pig farmers' representative bodies, together with the French swine veterinary practitioners' associations, voluntarily implemented a consensus decision to limit prescription and usage of all third- and fourth generation cephalosporins. ${ }^{1}$ This 
voluntary decision reserved the prescription of such antimicrobials to emergency cases, where the health of the animals was otherwise compromised and no alternate solution was at hand. In the meantime, the French Interprofessional Pork Council (Inaporc) wished to measure the compliance level of this voluntary moratorium, to measure the actual quantities of antibiotics used in the French pig sector (to compare them with species-specific estimates from the official yearly consumption figures from Anses -ANMV) and to gain enough detailed information to analyze the treatment patterns by animal category and indication for treatment. These objectives had to be fulfilled by adopting a pragmatic approach (i.e. without engaging into an exhaustive continuous prescription recording system).

With the scientific support of both the French Food Safety Agency (Anses) and the French Institute for pig and pork industry (Ifip), the working group opted for implementing a cross-sectional retrospective survey method within a representative sample of farms, which would allow rigorous data collection and provide reliable and detailed consumption estimates.

The objectives of this study were to describe the implementation of these surveys, to detail the consumption data and analyse the evolution of antimicrobial usage over a three-year period (2010-2013).

\section{Methods}

The European Medicines Agency, within the framework of the European Surveillance of Veterinary Antimicrobial Consumption (ESVAC) project, recommended recently two methodologies for collecting data by animal species [6]: the implementation of a full coverage system ("census model") or of studies in a representative sample of farms. The latter method allows to estimate national consumption by species, weight-group and production category. Therefore, this was the approach chosen in 2011 and 2014 by the French working group 'antimicrobials in the swine industry', through the selection of farm samples representative of the national production in 2010 and 2013, respectively.

\section{Farm random sampling}

Previous on-farm surveys had been performed in Brittany, where over $50 \%$ of the national swine production is concentrated [7]. From these data, ${ }^{2}$ it was calculated that 127 randomly selected farms would provide a $15 \%$ precision level. In order for the samples to be representative of the French swine production, simple random sampling was then performed in the exhaustive national swine database of identification, BDPORC, ${ }^{3}$ of which were excluded boar studs, farms located in Corsica and in the French overseas territories. Of those were selected farms with more than 49 sows, and farms with less than
50 sows but with more than 99 places in postweaning and/or fattening units, to exclude backyard pigs owners from the sampling frame. The working group deliberately elected to maximise the size of the sample, and an objective of 150 farms was defined for each survey.

The representativeness of these samples was checked post hoc $\left(\mathrm{Chi}^{2}\right)$ through confrontation of the farms characteristics (self reported production orientation, location in Brittany - the densest swine production area in France, membership to a production structure and number of sows) to those in the whole BDPORC database and to the national agricultural census.

\section{Farm inclusion process}

In order to reach the pre-established target of 150 farms per studied year in 2010 and in 2013, 270 and 300 randomised farms were extracted from the national database, respectively.

For each sampled farm, an explanatory letter detailing the study's principles and objectives was mailed to the corresponding production structure and treating veterinarian (as recorded in the database). Then, these professionals presented the information to the farmers, who decided - or not - to participate. Participation was voluntary and was not object to any form of compensation.

\section{Farm data collection}

The process of data collection was segmented in three steps.

Upon reception of the farmers' acceptance, a questionnaire was mailed to them and/or a phone survey was performed, in order to collect the data needed for the calculation of the antimicrobials used on their farm the previous year. The collected data were:

- The technical and/or economical records ${ }^{4}$ allowing to estimate the farm's animal population potentially exposed to antimicrobials: number of sows, number of sold/slaughtered piglets/pigs.

- The complete list of rights-holders that had dispensed veterinary drugs and/or medicated feed to the farm that year.

The latter designated structures were then contacted, and asked to send the detailed list of VMPs containing antimicrobials that had been sold to each voluntary farmer that year. The lists were required to mention the complete products' name, presentation including concentration, and quantities dispensed. For medicated feed, volume (tons), active substance(s) included in the feed and proportion (in ppm) were asked for. 
Finally, detailed data on the way farmers used VMPs were collected through phone interviews. Questions targeted:

- The treated production stage(s): sows (including boars/gilts), suckling piglets, weaned piglets or fattening pigs. When the same VMP was administered to several production stages, the number of commercial units was dispatched according to the farmer's declaration.

- The indication for the usage: the farmers were asked to mention the cause(s) of each treatment administered with the VMPs recorded (up to three indications per notified treatment were accepted). Each declared cause was later reclassified into one of the nine following indications: digestive, respiratory, locomotion, nervous, genito-urinary, cutaneous, udder/lactation disorders, or systemic condition. All types of treatments (i.e. individual as well as group treatments) were taken into account.

\section{Indicators for antimicrobial consumption}

The amount of active substance used on a given farm was derived from the quantity of each VMP declared as dispensed to the farmer. Antimicrobial usage on that farm was secondarily expressed in different indicators, since no antimicrobial exposure unit was harmonised in Europe at the time $[5,8]$ :

- The number of course dose per animal, either produced (piglets, weaners, fatteners) or present (sows) (nCD/ animal), was calculated by the equation:

[1] $\{[$ (quantities of active substance in $\mathrm{mg}) /($ dose in $\mathrm{mg} /$ $\mathrm{kg} / \mathrm{d} \mathrm{x}$ duration in $\mathrm{d} \mathrm{x}$ weight group in $\mathrm{kg})] /$ number of animals\}, where $d$ is for days;

- The number of daily dose per produced or present animal (nDD/ animal) was calculated by the equation:

[2] \{[(quantities of active substance in $\mathrm{mg}$ )/(dose in $\mathrm{mg} /$ $\mathrm{kg} / \mathrm{d} \mathrm{x}$ weight group in $\mathrm{kg})] /$ number of animals\}.

For these calculations, the dosage and duration values used were those set by the French veterinary medicines agency [9]. They have been defined for each VMP and take in consideration the highest dosage and duration values that are mentioned for swine in each VMP's summary of product's characteristics (SPC). The weight groups selected were $250 \mathrm{~kg}$ for a sow, $2 \mathrm{~kg}$ for a suckling piglet, $15 \mathrm{~kg}$ for a weaner and $50 \mathrm{~kg}$ for a fattener (live-weight).

The third selected indicator was the ALEA (Animal Level of Exposure to Antimicrobials), which is used by the national authorities to report on the yearly monitoring of antibiotic sales [8]. It is calculated as follows:

[3] \{[(quantities of active substance in $\mathrm{mg}) /($ dose in $\mathrm{mg} /$ $\mathrm{kg} / \mathrm{d} \mathrm{x}$ duration in $\mathrm{d}$ )]/biomass in $\mathrm{kg}$, where biomass is the sum of the number of sows times $300 \mathrm{~kg}$, plus the number of slaughtered finishers times $105 \mathrm{~kg}$, plus the number of culled sows times $350 \mathrm{~kg}$.

The ALEA value was calculated for each sample of farms.

In addition, the frequencies of farms dispensed with given antimicrobial classes at given production stages were also retrieved from the collected data.

This multi-indicator approach allows to calculate usage levels at farm as well as at sample levels, for each production stage, for each administration route, for each antimicrobial class and indication of treatment.

\section{Data analysis}

The disparity in antimicrobial usage between farms was explored with the Lorenz curve and captured through the proportion of high-consuming farms (proportion of farms that consume more than $50 \%$ of total $\mathrm{nCD} /$ animal in a given year per production stage).

The collected data were compared for each studied year (2010 and 2013) to those provided by the national monitoring programme $[9,10]$ overall and for each antimicrobial class, using the ALEA.

To detail the evolution of antimicrobial quantities used per production stage, antimicrobial class and indication, the number of daily doses per animal of both farms samples (2010 and 2013) were compared. Also, the proportions (frequencies) of farms using each antimicrobial class, or each treatment route, or concerned by each indication were compared with a $\mathrm{Chi}^{2}$ test. Quantitative results expressed with non-normally distributed indicators (e.g. nDD/animal) were compared through a Kruskall-Wallis test.

A 5\% threshold was selected for the designation of a statistically significant difference. The SAS software was used. 


\section{Results}

\section{Constitution of the samples of farms}

Both samples were within the predetermined target of 150 farms per studied year: 171 farms in 2010 and 157 in 2013 accepted to participate and provided nearcomplete data. In both cases, the participation rate was over 75\%: 45 and 53 farmers declined to be included in the samples, respectively (other farms were excluded from the samples because they did not meet inclusion criteria: on-going depopulation or works on site and change in the production type with variation of the numbers of produced animals). Furthermore, nine of the farmers included in the 2013 sample declined to answer to the part of the phone survey detailing the causes of treatments (due to time constraints).

The representativeness of both samples, when assessed against the data of their respective national agricultural census, was confirmed (Table 1).

\section{Overall estimation of the swine exposure to antimicrobials}

The 2010 national survey of antimicrobial sales reported an ALEA of 1.22 [9] whereas the farm sample provided an ALEA of 0.88 for that same year. This difference is essentially explained by four antimicrobial classes: in the sample, antimicrobial exposure to tetracyclines, macrolides, sulphonamides and trimethoprim is respectively 36\%, $37 \%$, $48 \%$ and $47 \%$ lower than in the pre-mentioned national sales monitoring report.

The 2013 farm sample provides an ALEA of 0.82. For that same year, the national report on antimicrobial sales calculates an ALEA of 0.96 [5]. Most of this difference is explained by one antimicrobial family: in the sample, exposure to tetracyclines is found $26 \%$ lower than in the national sales monitoring report.

The difference between the exposure values obtained by the two methods was not statistically significant $(p>0.05)$ and tended to decrease (28\% higher in the 2010 national monitoring data, and 16\% higher in 2013).

The comparison of exposure levels three years apart shows a significant reduction in antimicrobial usage $(p<$ $0.001)$ either through the national monitoring programme $(-21 \%)$ or the sample surveys $(-7 \%)$.

\section{Relative importance of the production stages in antimicrobial usage}

Sow treatments weighed $1 \%$ of the total treatments recorded (nCD/animal) in both samples (i.e. 2010 and 2013). Suckling piglets accounted for $30 \%$ of the amount of nCD/animal in 2010 and $24 \% 3$ years later. Weaned piglets accounted for 59\% (in 2010) and 64\% (in 2013) of the amount of $\mathrm{nCD} / \mathrm{animal}$, making the post-weaning stage the object of the majority of treatment. Finishers represented 9 and $11 \%$ of the amount of $\mathrm{nCD} /$ animal in 2010 and 2013, respectively.

\section{Evolution of usage in sows}

Antimicrobial usage in sows was found to increase between 2010 and 2013 ( $+17 \%$ of $\mathrm{nDD} /$ animal, $p>0.05$ ). There was however a statistically significant decrease in the usage of cephalosporins over the same period $(-80 \%$, $p<0.05$ ) (Table 2). There was a reduction of the proportion of high-consuming sow-farms (from $20 \%$ to $13 \%$ ), which did not reach statistical significance.

\section{Evolution of usage in suckling piglets}

Parenteral antimicrobial usage in suckling piglets was significantly reduced $(-29 \%$ of $\mathrm{nDD} /$ animal) between 2010 and $2013(p=0.05)$ (Table 2). The most drastic decrease was observed for cephalosporins $(-89 \%)$. This reduction reflects the scarcity of this usage: $4 \%$ of the farms used cephalosporins in 2013, versus $18 \%$ in 2010.

Table 1 Characteristics of the farms samples studied in 2010 and 2013, and comparison to the national data

\begin{tabular}{|c|c|c|c|c|c|}
\hline & & \multicolumn{2}{|l|}{2010} & \multicolumn{2}{|l|}{2013} \\
\hline & & national reference & farm sample & national reference & farm sample \\
\hline \multicolumn{2}{|c|}{ Farms located in Brittany ${ }^{a}$} & $51 \%$ & $46 \%$ & $49 \%$ & $45 \%$ \\
\hline \multicolumn{2}{|c|}{ Member of a production organisation ${ }^{a}$} & $83 \%$ & $84 \%$ & $85 \%$ & $89 \%$ \\
\hline \multirow[t]{3}{*}{ Production orientation } & Farrowing or farrow-to-weaning & $7 \%$ & $6 \%$ & $5 \%$ & $5 \%$ \\
\hline & Farrow-to-finish & $46 \%$ & $47 \%$ & $45 \%$ & $45 \%$ \\
\hline & Post-weaners, post-weaners to finish or finishers & $47 \%$ & $47 \%$ & $50 \%$ & $50 \%$ \\
\hline \multirow[t]{4}{*}{ Number of sows } & 5 to 49 & Not available & & $9 \%$ & $9 \%$ \\
\hline & 50 to 99 & & & $10 \%$ & $10 \%$ \\
\hline & 100 to 199 & & & $42 \%$ & $42 \%$ \\
\hline & 200 and more & & & $39 \%$ & $39 \%$ \\
\hline
\end{tabular}

${ }^{a}$ National reference data from the national database BDPORC, extracted for years 2010 and 2013. Other national reference data are from the department of statistics of the French Ministry of Agriculture. There was no statistical significant difference, within each year, between the sample's criteria and those of the national reference (Chi-2 test) 


\section{Evolution of usage in weaned piglets}

Antimicrobial usage in weaned pigs decreased between 2010 and 2013 (-19\% of nDD/animal), a highly significant result $(p=0.006)$. The usage of medicated feed (directly reflected by premix) was reduced by $25 \%$, whereas there was no significant evolution for oral powders and solutions $(+8 \%$ of $\mathrm{nDD} / \mathrm{animal})$ and injectable forms $(-4 \%$ of $\mathrm{nDD} /$ animal). The consumption of four antimicrobial classes was significantly reduced $(p<0.05)$ : lincosamides $(-51 \%)$, tetracyclines $(-32 \%)$, polymyxins $(-22 \%)$ and macrolides (-19\%).

As the Lorenz curves show (Fig. 1, Table 2), 50\% of the treatment courses were performed by $25 \%$ of farms in 2010 and $18 \%$ in 2013, this reduction of the proportion of high-consuming farms was also observed for other production stages (Table 2).

\section{Evolution of usage in fatteners}

Antimicrobial usage in fatteners decreased between 2010 and 2013 ( $-29 \%$ of $\mathrm{nDD} / \mathrm{animal})$, without reaching statistical significance $(p=0.09)$. Again, the use of medicated feed has been significantly reduced for both indicators: $\mathrm{nDD} /$ animal $(-64 \%, p<0.05)$ and proportion of farms using this mode of treatment (from 29 to $16 \%$ of the farms in the respective samples). There is a strong, although non-significant, increase in the usage of oral powders and solutions ( $+54 \%$ of $\mathrm{nDD} /$ animal).

Although four out of five antimicrobial classes displayed a numerical reduced usage, this reached statistical significance in a single family (i.e. penicillins, $-14 \%$ ).

\section{Evolution of indications for treatment}

There was a significant increase in the proportion of farms where sows were treated for locomotor disorders (Table 2) between 2010 and 2013. This indication remained however limited (3\% of the $2013 \mathrm{nDD} /$ animal), as compared to the dominant indication for antimicrobial treatment (urogenital disorders, 65\%). The motivations for treatment were not significantly affected either, except for the locomotor disorders $(+150 \%$ of $\mathrm{nDD} /$ animal between 2013 and 2010, $p<0.05$ ).

In suckling piglets, the frequency of the dominant indications (respiratory and locomotor disorders) decreased $(-22 \%$ and $-17 \%$, respectively of $\mathrm{nDD} / \mathrm{animal})$, without reaching statistical significance. However, the proportion of farms where such treatments took place remained stable (respectively $64 \%$ and $58 \%$ in 2013). Regarding post-weaning, a significant drop occurred in the proportion of uses for digestive disorders $(-29 \%$ of $\mathrm{nDD} / \mathrm{animal})$ that are the dominant indication (62\% of the amounts used in 2013). The proportion of farms where these treatments were performed did not significantly change (88\% of concerned farms in 2013). Conversely, even though the proportion of uses for locomotor diseases decreased $(-78 \%$ of $\mathrm{nDD} /$ animal), the proportion of treated farms increased significantly (from 29 to $51 \%$ ). In finishers, the two dominant indications for treatment (digestive and respiratory disorders) did not present significant changes between 2010 and 2013.

\section{Discussion}

\section{Representative sample of farms methodology}

The strong positive response rate of the farmers to the request for participating in the samples, observed both in 2010 and 2013 (>75\%), while no counterpart was offered in our protocol, reflects a lasting strong motivation of farmers in supporting the study and tackling the issue of veterinary antimicrobial consumption. This also indirectly reflects the strong empowerment by the production organisations and the swine veterinarians in France on this subject. This is further substantiated by the initiative from swine industry representatives (both farmers and veterinarians) of a voluntary moratorium on 3rd and 4th generation cephalosporins in swine production. Announced in November 2010, this moratorium entered into effect by spring 2011, and was subject to wide national media coverage. On the other hand, the French ministry of Agriculture launched in June 2012 a plan to reduce by $25 \%$ veterinary antimicrobial consumption within 5 years, EcoAntibio 2017, ${ }^{5}$ and this might also have positively influenced the enrolment of farmers in the 2013 sample.

All the quantitative 2010 and 2013 data were harvested from reliable and comprehensive sources: acquired antimicrobial quantities were provided by the dispensing structure for each farm, from the list of providers that had been issued by each farmer, and yearly swine production was extracted from the farmers' accounts.

The representativeness of each sample with the national swine herd population was verified against data from the two most recent agricultural censuses (2010 and 2013). Both samples being found representative, this provides robustness to the data on antimicrobial usage collected in both these instances. This allowed comparing the results obtained in each of the samples (evolution), and also with the national sales data, monitored by the French authorities.

\section{Total usage evolution between 2010 and 2013}

In both years studied, the ALEA calculation of total usage of antimicrobials in the samples was found different from that estimated by the French authorities. This disparity is reduced for the 2013 data (15.6\% difference) as compared to 2010 ( $27.6 \%$ difference). It is striking that in both years, the calculation indicates a lower swine exposure to antimicrobials than the national estimates do. In the case of the sales monitoring, the attribution to the swine species is indicated by the 


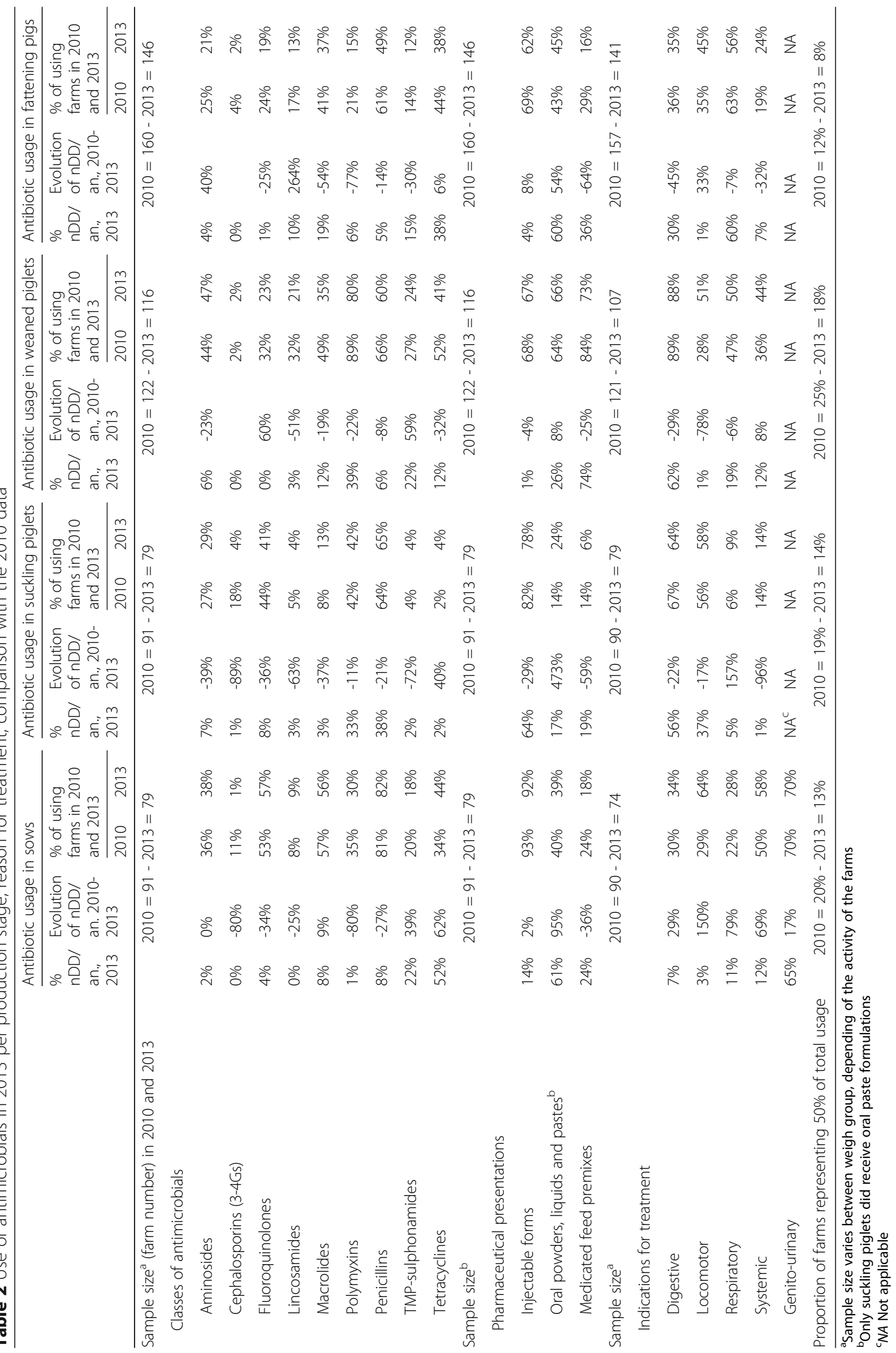




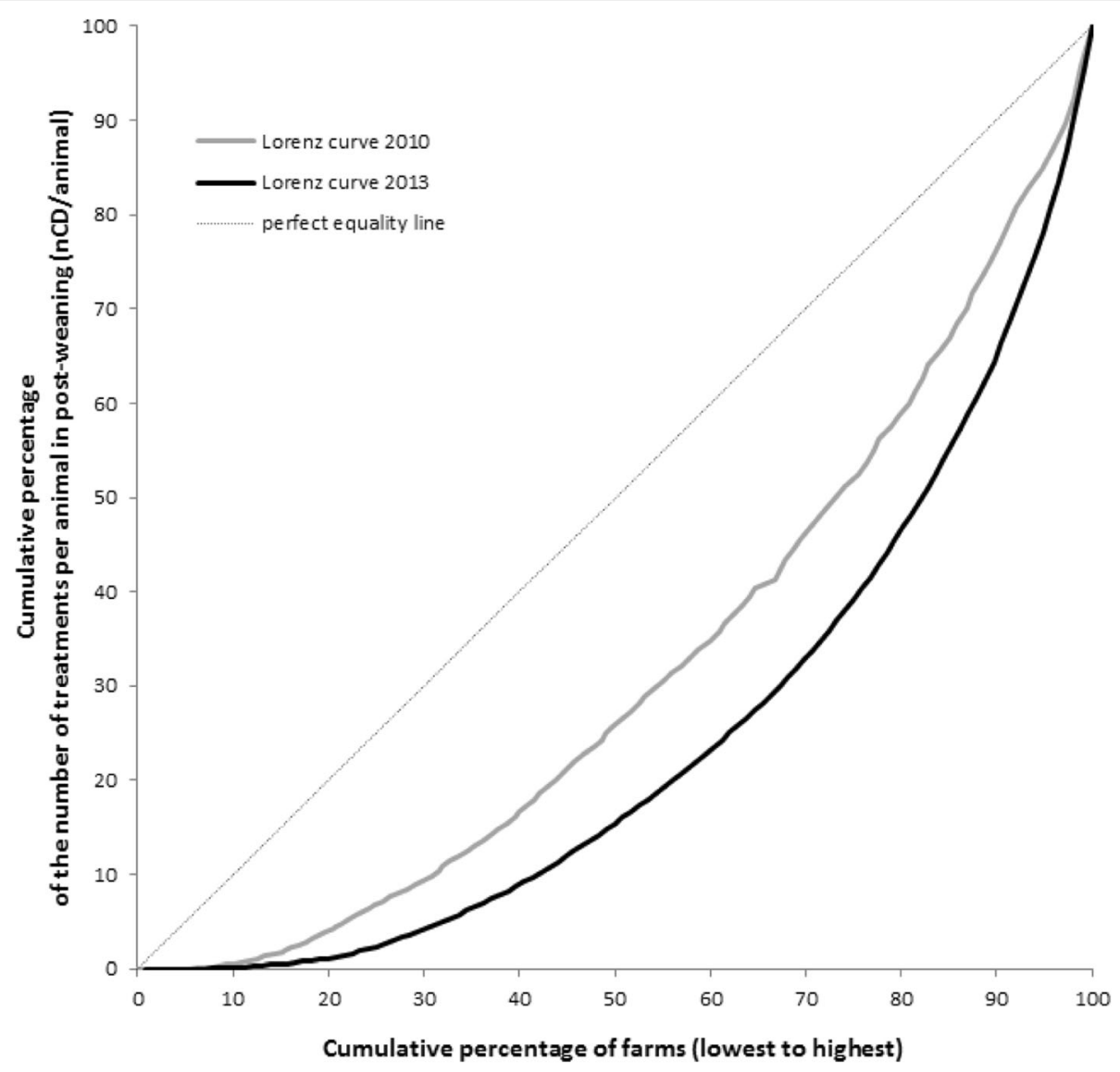

Fig. 1 Distribution of postweaning uses (nDD/animal) in the 2010 and 2013 samples of farms (Lorenz curves)

manufacturers, while the sample of farms methodology collects on-farm usage data. As such, the outcome of the latter is most probably closer to the actual antimicrobial swine exposure level at national level.

In fact, the single important difference between the samples' and authorities' ALEA values is for tetracyclines suggesting that the sales of this antimicrobial class to the swine industry are overestimated by the pharmaceutical industry in their notification to the French Veterinary Medicines Agency, possibly because most corresponding VMPs are registered for a multi-species usage.

In any case, both sources concur in confirming a highly significant drop in antimicrobial consumption in the French swine industry over the three years considered. This is consistent with the recent comparison of three methods for stratifying antimicrobial sales data per animal species in Switzerland (equal distribution, biomass distribution and longitudinal study extrapolation), in reference to a detailed recording system of prescriptions [11], where all methods found comparable trends, with marginal differences regarding the swine species. Furthermore, a cross-sectional study, based on voluntary participation of swine veterinarians and farmers, was successfully performed in Germany for the year 2011, providing results in line with national antimicrobial sales data [12].

However, the 7\% reduction in the value of the ALEA observed thanks to the sample methodology between 2010 and 2013 does not accurately reflect the extent of the changes in antimicrobial usage in suckling piglets, weaned pigs and finishing pigs, the dominant stages as far as antimicrobial consumption is concerned. It may largely be explained by the sensitivity of this indicator to the treatments ascribed to sows, since it processes a percentage of treated liveweight: a $300-\mathrm{kg}$ sow will have a onehundred-fold more important impact on the ALEA than the treatment of a 3-kg pig would. Since the 2013 sample recorded a (non-significant) increase in sows' treatments, the drop in total exposure was - arithmetically - limited through this methodology. These considerations on the reduction of usage of antimicrobial VMPs in France are indirectly substantiated by the recently published study of the evolution of animal health expenses in swine farms [13]. After having plateaued between 2006 and 2011, treatment products expenditures (in $€$ ) dropped by $18 \%$ within two years $(-20 \%$ for in-feed supplementations and $-15 \%$ 
for parenteral products) while vaccine expenses increased by $10 \%$. Although that study extends from 2002 to 2012 in farrow-to-finish French farms and that expenses are not explicitly related to amount used, it evidences that significant changes occurred between 2010 and 2012. In Denmark, an increase of vaccine usage has also been observed concurrently with a decrease in antimicrobial consumption that followed the announcement and introduction of the Yellow Card intervention [14], even though the use of vaccines does not explain per se a drop in antibiotic usage [15].

The decrease in total antimicrobial consumption in France reflects the positive attitude of swine farmers and practitioners toward reducing antimicrobial usage. It is temporally associated with wide and extensive national media coverage of the French Ministry of Agriculture's announcements on the national plan on reduction of veterinary antimicrobial usage; such a temporal association has also been observed in Denmark [13] and the Netherlands [16].

For the moment, this reduction has mostly been achieved through a partial shift in the treatment mode, with a strong and highly significant reduction of in-feed supplementation for weaners ( $-25 \%$ of $\mathrm{nDD} /$ animal between 2013 and 2010) and a lower - non-significant increase of drinking-water soluble products used postweaning (+ $8 \% \mathrm{nDD} /$ animal).

The units in which national reports on antimicrobial consumption are presenting yearly results have also long been left un-harmonised, hampering international comparisons [5, 17-20]. The recent proposal of harmonised DDDvet and DCDvet units in Europe [8] will resolve this issue for the calculation of the numerator of the concerned indicators. However, it can be observed that in Germany in 2011 [11] tetracyclines were quantitatively the most commonly used antimicrobials on swine farms, while in France they ranked second in 2013. In another cross-sectional study in four European member states, where data collection took place in 2012-2013, aminopenicillins were found to be the antimicrobial class the most commonly used in all countries [21]. However, indicators differ and the numbers of sampled farms were more limited than in the present French and the recent German [11] studies.

\section{Usage in sows}

This study evidenced a trend of increasing antimicrobial usage in sows (+17\% of $\mathrm{nDD} / \mathrm{animal})$ over the 3 -year period. Although not of absolute evidence, the impact of transition to sow group-housing (Council Directive $2008 / 120 / E C$ ) seems to have been the main driver of this evolution. It is well known that the French swine industry was behind schedule to implement this European regulation, as were 5 other Member States [22]. This has resulted in extensive and widespread building works in farm facilities over 2012-2013, which might have disturbed farms' management and routine - and stressed the animals. The observed increase in most treatment motivations is in favour of such a temporary unbalance of the farms' global sanitary situation around 2013. Additionally, a cross-sectional study involving 108 farms in western France identified group-housing in large groups of sows as a significant risk factor associated with leg problems [23]. Also, in German study, where transition to group-housed sow breeding had been performed with more anticipation, the main indication for treatment in sows was found to be respiratory diseases; not leg disorders [11].

Taken together, these elements may explain the significant increase in treatments for locomotor disorders observed in 2013 in sows $(+150 \%)$ on a wide array of farms $(+35 \%)$.

Also, an increase in the incidence of clinical leptospirosis has been described in association with loose-housing of sows in Denmark [24]. This was reported as having resulted in a wide usage of leptospirosis vaccination in sow herds. In France, no commercial vaccine was available for prevention of leptospirosis in sows at the time of the study, but the $17 \%$ increase observed in 2013 for genitourinary disorders and the parallel increase in the usage of tetracyclines in sows might at least partly reflect an increase in leptospirosis control strategies.

After this adaptation phase, follow-up studies should allow to evaluate whether antimicrobial consumption of sows remains at the 2013 level, or whether it follows the decreasing trend observed in the other production stages. A 2016 sample of farms has recently been constituted and is being subject to interviews at the time of submission of the present manuscript, in accordance with the herein detailed protocol.

\section{Usage in suckling piglets}

Antimicrobial usage has been significantly reduced between 2010 and 2013, the strongest drop being for cephalosporins. None of the treatment indications frequency increased over that period, which might suggest that the change in antimicrobial usage was accompanied by changes either in piglet management/care or in sow preparation, or both.

The bottom-up approach chosen for the present study allows to discriminate exposure levels in sows and suckling piglets, which is not performed in other national monitoring programmes such as Denmark [25] or the Netherlands [26] hampering comparison of results.

Finally, one of the main objectives fixed by Inaporc at the start of the study was reached: the voluntary ban on 3rd and 4th generation cephalosporins that started in spring 2011 was widely implemented on French farm, in a measurable way. 


\section{Usage in weaned pigs}

Postweaning remains the most antimicrobial-exposed production stage, as in other European countries, whatever the methodology used for monitoring [11, 20, 26]. Between 2010 and 2013, this production stage benefited from the decreased use of in-feed antimicrobial supplementation (i.e. medicated feed, since top-feeding is not allowed in France), and although the proportion of farms using polymyxins remained high, there was a $22 \%$ drop in its usage (in nDD/animal) over the period. Most remarkably, all antimicrobial classes were found to have a decreased usage (statistically significant for 4 out of 6 of them) - with the notable exception of potentiated sulphonamides $(+59 \%)$, whose increase did not reach statistical significance. This impact of the putative switch from in-feed to water administration of antimicrobials could be expected since the duration of each treatment course [27] (and corresponding number of daily dose) is more limited through water medication than direct infeed manufacturing.

In the present case, although digestive disorders remained the dominant cause of postweaning treatments, their relative importance regarding antimicrobial consumption of this production stage dropped significantly. The usage of zinc oxide had not been authorised before 2016 in France, and a new vaccine against oedema disease had just reached the market in 2013. It can safely be inferred that treatment strategies of digestive disorders have profoundly changed during the study period, less relying on in-feed supplementation over extended durations, and more on short-term targeted treatments via drinking water.

\section{Usage in fatteners}

As for weaners, usage of in-feed supplementation was strongly (and significantly) reduced among finishers between 2010 and 2013. The main difference was that only a single class of antimicrobials was significantly affected (i.e. penicillins), whereas tetracyclines, which are the main class of antimicrobials used at this production stage, were not.

The dominant indication for treatment were the respiratory diseases in finishers, both in 2010 and 2013, which is consistent with the results of the German survey performed with the 2011 data [12], but is different from the outcome of a retrospective Danish study where gastro-intestinal dominated the indications for treatment for the 2002-2008 period [28]. However the frequency of respiratory diseases as an indication for treatment was on an increasing trend (+81\% per finishing pig produced) while that of gastro-intestinal diseases was decreasing, which clearly places this indication as an emerging clinical entity. Also, large variation in antimicrobial usage patterns have been described between
European countries, as analysed for the 2008-2013 period between Denmark and Switzerland [29].

\section{Limitations of the study}

Although all treatments are compulsorily recorded by the farmer in the farm logs, as required by EU and national $^{6}$ regulations, the description of antimicrobial usage may be subject to memory bias, since interviews were conducted on the year following actual usage (end of 2011 and early 2012 for the 2010 sample survey; 2014 for the 2013 one). This bias is however limited since it can affect the attribution of the treatment to one of the other of the production stages, but not the quantities used on the farm. Also, this bias is almost excluded for in-feed supplementation, since all production stages are clearly identified through the nature of the feed delivered to the farms. The motivation for treatments was more prone to such a recall bias; in a limited extent however: in $6 \%$ farms, the motive of suckling piglets' treatment could not be defined by the farmers, and this proportion was at most $12 \%$ for the post-weaning stage, in 2010. For 2013, these proportions were nil regarding sows and suckling piglets, and 4 and $3 \%$ in post-weaning and finishing stages, respectively.

\section{Conclusion}

Important and significant drops of antimicrobial usage were evidenced between 2010 and 2013, which comply with the national reduction target set up in 2012 of $25 \%$ by 2017 . These results reflect a strong sensitisation of swine production professionals to the antimicrobial reduction objectives, and are the result of pre-2012 voluntary measures, such as the moratorium on the use of 3rd and 4th generation cephalosporins. This sample methodology is currently renewed, in order to validate that the national targets have been met, and whether the reduction of post-weaning usages (partial substitution of in-feed medication by more occasional - and judicious - drinking water treatment) has remained in place, or even exceeded expectations.

\section{Endnotes}

${ }^{1}$ [in French]. Chouët S, Delsart M, Deville N, Dréau D, Lannou J, Lemistre A, Liber M, Marchand D, Normand V, Sevin JL, Sialleli JN. Consensus sur l'utilisation des céphalosporines de $3^{\mathrm{e}}$ et $4^{\mathrm{e}}$ générations en pathologie porcine. Bulletin des GTV, 2012 (64):55-56.

${ }^{2}$ Study by Chauvin, published by the French Food Safety Agency, Anses, in 2010, available (in French) at https:// www.anses.fr/fr/system/files/LABO-Ra-AntibioEtudPorcin.pdf

${ }^{3}$ BDPORC has a public informative website (in French) at http://www.bdporc.com/alertes/accueilAbonne.do 
${ }^{4}$ Most swine French farmers use a common performance data programme, developed, distributed and operated by IFIP. See at http://www.ifip.asso.fr/fr/resultatseconomiques-gttt-graphique.html (in French)

${ }^{5}$ For more information on the Plan EcoAntibio 2017 (in English), see: http://agriculture.gouv.fr/sites/minagri/ files/documents/pdf/130208PlanABR-GB-2012-BD_cle87 86a1.pdf (32 pages document). At the time of submitting this manuscript, this target has been reached.

${ }^{6}$ See French regulation: https://www.legifrance.gouv.fr/affich Texte.do?cidTexte=JORFTEXT000000583065 (in French).

\begin{abstract}
Abbreviations
ALEA: Animal Level of Exposure to Antimicrobials; ANMV: Agence Nationale du Médicament Vétérinaire (French Agency for Veterinary Medicinal Products); ANSES: Agence nationale de sécurité sanitaire de l'alimentation, de l'environnement et du travail (French Agency for Food, Environmental and Occupational Health \& Safety); BDPORC: Base de Données professionnelles PORCine (French swine database of identification); CD: Course dose; DD: Daily dose; ESVAC: European Surveillance of Veterinary Antimicrobial Consumption; IFIP: Institut technique de recherche et de développement de la filière porcine (swine industry's French technical institute); INAPORC: Interprofession nationale porcine (French Interprofessional Pork Council); SPC: Summary of Product's Characteristics; VMP: Veterinary Medicinal Product
\end{abstract}

\section{Acknowledgements}

The authors are grateful to Anne Chevance and Gérard Moulin from Anses-ANMV for their support.

The French Working Group 'antimicrobials in the swine industry' was composed, at the time of the 2010 and 2013 farm sample studies, of: Philippe Le Coz, DVM and Jean-Luc Sévin, DVM for the National Society of the Technic Veterinary Groups (SNGTV), Mélanie Liber, DVM, for the Western France Porcine Veterinary Association (AVPO), Sylvie Chouët, DVM, Arlette Laval, DVM and Jeanne Dupuis, DVM for the French Branch of the International Pig Veterinary Society (AFMVP), Jeff Trébaol and Caroline Tailleur, for the National Swine Production Federation (FNP), Yves Da Ros, Philippe Amar, DVM and Valérie Bris, for the national Agricultural Cooperative Union (Coop de France), Patrick Gambade, DVM, Estelle Morgand and Bruno Toussaint for the National Feed Industry Union (SNIA), Nathalie Chatelier, DVM and Joseph Gérard, for the Gathering of Western France Meat Production Groups (UGPVB) and Roxane Rossel, DVM, for the Aquitaine interprofessional Swine association (INPAQ).

\section{Funding}

Inaporc funded the study.

\section{Availability of data and materials}

The data that support the findings of this study are available from Ifip, but restrictions apply to the availability of these data, which were used under consent of anonymity from the farmers included in the samples and from the dispensing rights-holders. Data are however available from the authors upon reasonable request and with permission of Anne Hémonic (corresponding author).

\footnotetext{
Authors' contributions

Hémonic Anne, Chauvin Claire, Delzescaux Didier, Verliat Fabien, Corrégé Isabelle contributed to the study conception and design. Hémonic Anne and Corrégé Isabelle supervised data acquisition. Hémonic Anne, Chauvin Claire, Delzescaux Didier, Verliat Fabien, Corrégé Isabelle and the Working group contributed to interpretation of the data. Hémonic Anne and Chauvin Claire drafted and critically revised the manuscript. All authors read and approved the final manuscript.
}

\section{Ethics approval and consent to participate}

A consent form was completed by all the farmers prior to the enrolment in the samples.

\section{Consent for publication}

All authors consent to the publication of the present manuscript.

\section{Competing interests}

Delzescaux Didier and Verliat Fabien are employees from the sponsor.

\section{Publisher's Note}

Springer Nature remains neutral with regard to jurisdictional claims in published maps and institutional affiliations.

\section{Author details}

${ }^{1}$ IFIP-Institut du porc, Domaine de la Motte au Vicomte, 35104, 35651 Le Rheu, BP, France. ${ }^{2}$ Anses Laboratoire de Ploufragan-Plouzané, 53, 22440 Ploufragan, BP, France. ${ }^{3}$ Inaporc, 149 rue de Bercy, 75595, 12 Paris Cedex, France.

Received: 21 November 2017 Accepted: 26 January 2018

Published online: 17 April 2018

\section{References}

1. FAO/OIEMHO Tripartite Alliance. WHO, FAO, and OIE unite in the fight against Antimicrobial Resistance. 2010, 2 p. http://www.oie.int/fileadmin/Home/eng/ Media_Center/docs/pdf/FAO_OIE_WHO_AMRfactsheet.pdf

2. OIE. Antimicrobial Resistance Fact sheet. 2015, 2 p. http://www.oie.int/fileadmin/ Home/eng/Media_Center/docs/pdf/Fact_sheets/ANTIBIO_EN.pdf

3. European Medicines Agency. Sales of veterinary antimicrobial agents in $29 \mathrm{EU} /$ EEA countries in 2014. 2016, 176 p. http://www.ema.europa.eu/ema/pages/ includes/document/open_document.jpp?webContentld=WC500214217

4. Collineau L, Belloc C, Stärk KD, Hémonic A, Postma M, Dewulf J, Chauvin C. Guidance on the selection of appropriate indicators for quantification of antimicrobial usage in humans and animals. Zoonoses Public Health. 2017; 64(3):165-84.

5. Anses-ANMV. Sales survey of Veterinary Medicinal Products containing Antimicrobials in France- 2015. 2016, 105 p. https://www.anses.fr/en/ system/files/ANMV-Ra-Antibiotiques2015EN.pdf

6. European Medicines Agency. Draft guidance on provision of data on antimicrobial use by animal species from national data collection systems. 2017, 36 p. http://www.ema.europa.eu/docs/en_GB/document_library/ Scientific_guideline/2017/03/WC500224492.pdf

7. Chauvin C, Le Bouquin S, Sanders P. Use of antimicrobials in the pig, poultry and rabbit sectors in France -survey results. Bulletin Épidémiologique Santé Animale-Alimentation. 2012;53:12-5. https://pro.anses.fr/bulletin-epidemiolo gique/Documents//BEP-mg-BE53EN.pdf

8. EMA. "Defined daily doses for animals (DDDvet) and defined course doses for animals (DCDvet)". EMA/224954/2016, 29 p. http://www.ema.europa.eu/ docs/en_GB/document_library/Other/2016/04/WC500205410.pdf

9. Anses-ANMV. Sales survey of Veterinary Medicinal Products containing Antimicrobials in France - 2013. 2014, 78 p. https://www.anses.fr/en/system/ files/ANMV-Ra-Antibiotiques2013EN.pdf

10. Anses-ANMV. Sales survey of Veterinary Medicinal Products containing Antimicrobials in France - 2010; volumes and estimated consumption of antimicrobials in animals. 2011, 56 p. https://www.anses.fr/en/system/files/ ANMV-Ra-Antibiotiques2010EN.pdf

11. Carmo LP, Schüpbach-Regula G, Müntener C, Chevance A, Moulin G, Magouras I. Approaches for quantifying antimicrobial consumption per animal species based on national sales data: a Swiss example, 2006 to 2013. Euro Surveill. 2017;22(6):pii=30458. http://eurosurveillance.org/images/ dynamic/EE/N22N06/art22710.pdf

12. van Rennings $L$, von Münchhausen $C$, Ottilie $H$, Hartmann $M$, Merle $R$, Honscha W, Käsbohrer A, Kreienbrock L. Cross-sectional study on antibiotic usage in pigs in Germany. PLoS One 2015;10(3): e0119114. http://journals. plos.org/plosone/article/file?id=https://doi.org/10.1371/journal.pone. 0119114\&type=printable

13. Corrégé I, Badouard B, Hémonic A. Medication costs in French pig farms: evolution and herd typology [in French]. Journées de la Recherche Porcine. 2014;46:147-52. http://www.journees-recherche-porcine.com/texte/2014/ sante/3S3.pdf

14. Jensen V, de Knegt L, Andersen V, Wingstrand A. Temporal relationship between decrease in antimicrobial prescription for Danish pigs and the "yellow card" legal intervention directed at reduction of antimicrobial use. Prev Vet Med. 2014;117(3-4):554-64.

15. Kruse A, de Knegt L, Nielsen L, Alban L. No clear effect of initiating vaccination against common endemic infections on the amounts of prescribed antimicrobials for Danish weaner and finishing pigs during 2007- 
2013. Front Vet Sci. 2017;3:120. http://journal.frontiersin.org/article/https:// doi.org/10.3389/fvets.2016.00120/pdf

16. Speksnijder D, Mevius D, Bruschke C, Wagenaar J. Reduction of veterinary antimicrobial use in the Netherlands. The Dutch success model. Zoonoses Public Health 2015; 62 Suppl 1:79-87. http://onlinelibrary.wiley.com/doi/ https://doi.org/10.1111/zph.12167/epdf

17. Chauvin C, Madec F, Guillemot D, Sanders P. The crucial question of standardisation when measuring drug consumption. Vet Res. 2001;32: 533-43. http://www.vetres.org/articles/vetres/pdf/2001/05/v1607.pdf

18. Jensen $V$, Jacobsen $E$, Bager $F$. Veterinary antimicrobial-usage statistics based on standardized measures of dosage. Prev Vet Med. 2004;64:201-15.

19. Bondt N, Jensen V, Puistier-Jansen L, van Geijlswijk I. Comparing antimicrobial exposure based on sales data. Prev Vet Med. 2013;108:10-20. https://doi.org/10. 1016/j.prevetmed.2012.07.009. http://ac.els-cdn.com/S0167587712002346/1-s2.0S0167587712002346-main.pdf?_tid=9670af54-2128-11e6-a550-00000aacb362\&ac dnat $=1464037068 \_854 d$ dececa05242b824c30dac2ae0f178

20. Taverne F, Jacobs J, Heederik D, Mouton J, Wagenaar J, van Geijlswijk I, SDa. Influence of applying different units of measurement on reporting antimicrobial consumption data for pig farms. BMC Vet Res. 2015;11:250 https:/academic.oup.com/jas/article-pdf/89/3/845/23632788/845.pdf

21. Sjölund M, Postma M, Collineau L, Lösken S, Backhans A, Belloc C, Emanuelson U, Beilage EG, Stärk K, Dewulf J. MINAPIG consortium. Quantitative and qualitative antimicrobial usage patterns in farrow-to-finish pig herds in Belgium, France, Germany and Sweden. Prev Vet Med. 2016;130:41-50.

22. Tuyttens F, Van Gansbeke S, Ampe B. Survey Among Belgian pig producers about the introduction of group housing systems for gestating sows. J Anim Sci. 2011;89(3):845-55. https://academic.oup.com/jas/article-pdf/89/ 3/845/23632788/845.pdf

23. Cador C, Pol F, Hamoniaux M, Dorenlor V, Eveno E, Guyomarc'h C, Rose N. Risk factors associated with leg disorders of gestating sows in different group-housing systems: a cross-sectional study in 108 farrow-to-finish farms in France. Prev Vet Med. 2014;116(1-2):102-10.

24. Friis N, Jorsal S, Sørensen V, Schirmer A, Lindahl J, Thorup F. Enzootics Of Leptospira abortion in Danish sow herds practising loose housing on deep straw bedding. Acta Vet Scand. 2000;41(4):387-90.

25. DANMAP. DANMAP 2015-Use of antimicrobial agents and occurrence of antimicrobial resistance in bacteria from food animals, food and humans in Denmark. 2016:144 p. http://www.danmap.org/ /media/Projekt\%20sites/ Danmap/DANMAP\%20reports/DANMAP\%20\%202015/DANMAP\%202015.ashx.

26. MARAN. Nethmap-MARAN 2016: Monitoring of antimicrobial resistance and antibiotic usage in animals in the Netherlands in 2014. 2016; 218 p. http:// www.wur.nl/upload_mm/3/7/f/b17aafd6-2954-4ef2-8717-0adddc4be0bc_ NethmapMaran2016_A.pdf.

27. Fortané N, Bonnet-Beaugrand F, Hémonic A, Samedi C, Savy A, Belloc C. Learning processes and trajectories for the reduction of antibiotic use in pig farming: a qualitative approach. Antibiotics. 2015;4:435-54.

28. Jensen VF, Emborg HD, Aarestrup FM. Indications and patterns of therapeutic use of antimicrobial agents in the Danish pig production from 2002 to 2008. J Vet Pharmacol Ther. 2012;35(1):33-46.

29. Carmo LP, Nielsen LR, Alban L, Müntener CR, Schüpbach-Regula $G$, Magouras I. Comparison of antimicrobial consumption patterns in the Swiss and Danish cattle and swine production (2007-2013). Front Vet Sci 2017; 4:26. http://journal.frontiersin.org/article/https://doi.org/10.3389/ fvets.2017.00026/pdf

\section{Submit your next manuscript to BioMed Central and we will help you at every step:}

- We accept pre-submission inquiries

- Our selector tool helps you to find the most relevant journal

- We provide round the clock customer support

- Convenient online submission

- Thorough peer review

- Inclusion in PubMed and all major indexing services

- Maximum visibility for your research

Submit your manuscript at www.biomedcentral.com/submit
(O) BioMed Central 